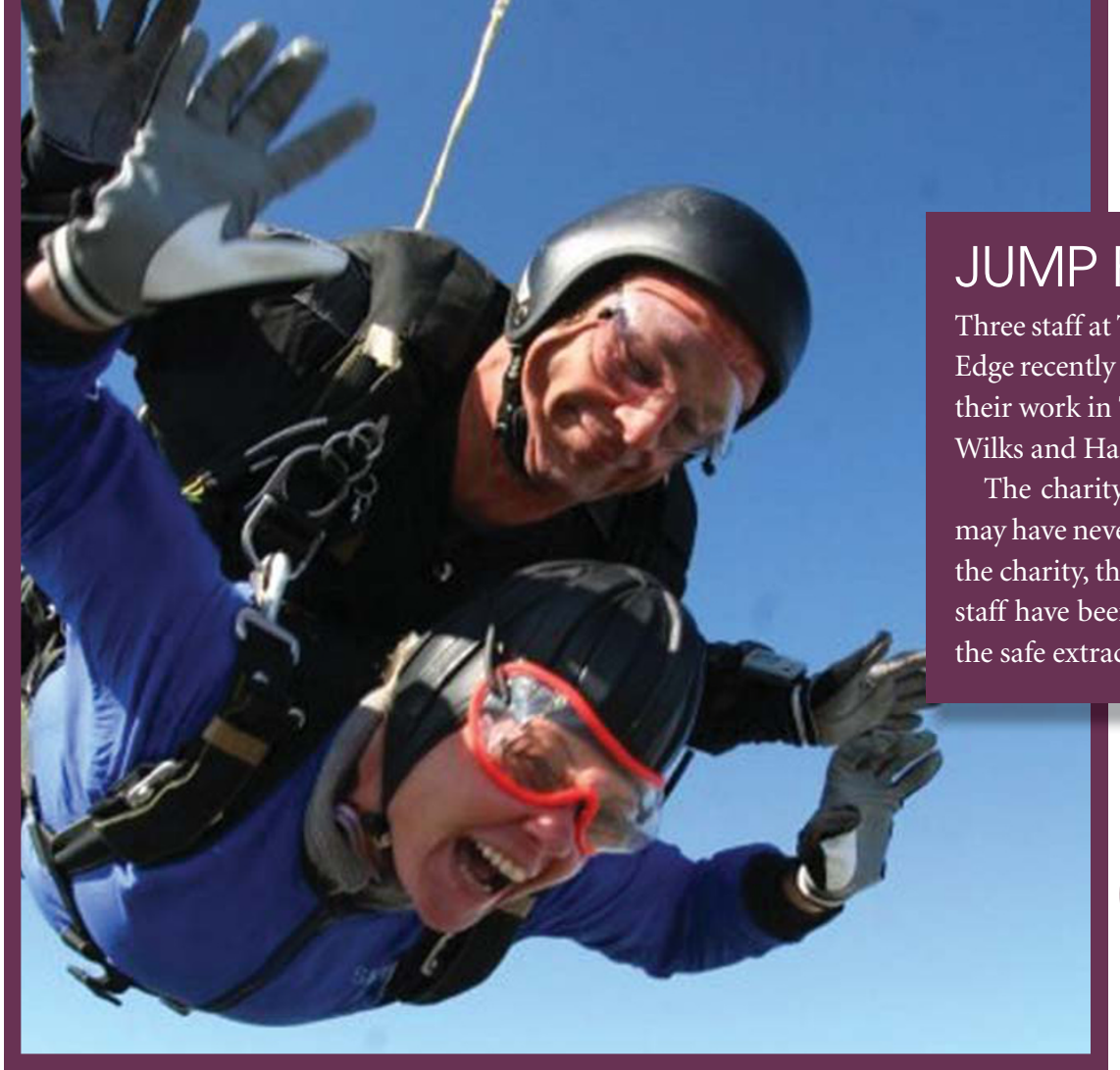

\section{NEW CHAIR APPOINTED}

Joanne Tyree has been appointed as the new chair of the National Oral Health Promotion Group (NOHPG). The NOHPG is a forum for professionals interested in the promotion of oral health and the group was established in 1981. The aim of the group is to encourage the continual development of Oral Health Promotion and to provide sup-

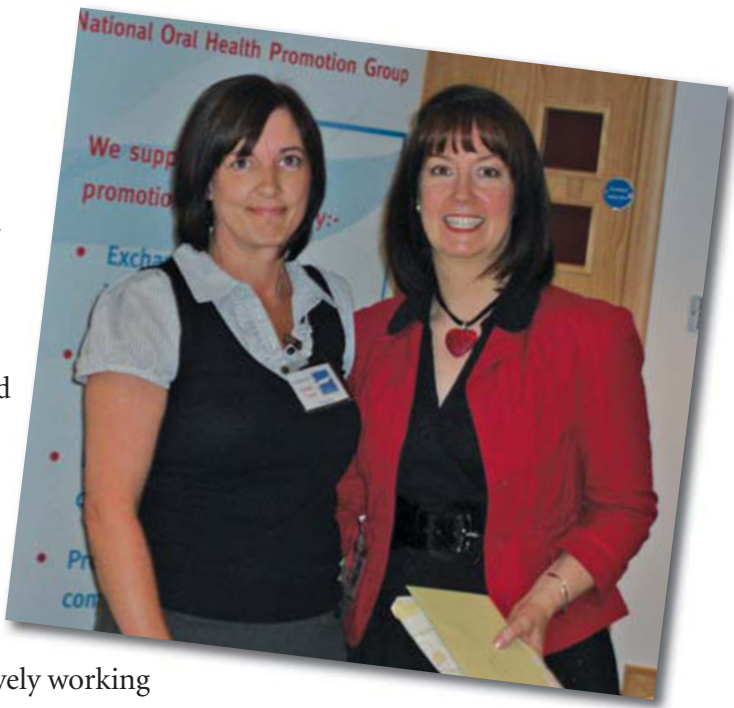

port to its members who are actively working in the field of Oral Health Education and Oral Health Improvement.

For more information about the group visit www.nohpg.org.
Three staff at The Chipping Manor Dental Practice in Wotton Under Edge recently did a charity skydive to raise money for Bridge2Aid for Tanzania. Dentist Dave Stephens and dental nurses Ali ilks and Hannah Wakefield undertook the jump. efth, working in very basic conditions.

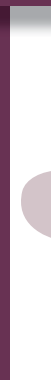

\section{DENTAL NURSES GAIN FLUORIDE VARNISH CERTIFICATES}

The first dental nurses in the South West of England have gained their certificate of competency in the application of topical fluoride varnish via blended learning. Alasdair Miller, Dental Postgraduate Dean, presented certificates to Tracy Andrews, Lindsey Bright and Claire Gillbard.

They completed a blended learning programme to achieve competency in the application of topical fluoride varnish as permitted by the General Dental Council's recent 'Scope of Practice' document.

The programme involved the use of distance learning workbooks which tested and updated the students' underpinning theoretical knowledge. There were also practical sessions in the Simulated Dental Learning Environment of the Peninsula Dental School in Plymouth followed up with successful completion of a patient logbook with the application of topical fluoride varnish carried out on ten patients under the close supervision of a dentist.

\section{NATIONAL AWARD FOR ORAL HEALTH TEAM}

A project to improve secondary school pupils' oral health has led to NHS Lanarkshire scooping the Patron's Prize at the National Oral Health Promotion Group's (NOHPG) annual conference, held in Manchester. The health board's oral health team, working with local schools, developed a new DVD and teaching materials called 'Smile with Confidence'.

Celia Watt, senior health promotion officer (oral health), said, 'We identified gaps in oral health knowledge and designed a resource that meets the needs of the pupils.'

Vital editor Kate Maynard (left) discussing Vital CPD with two curious delegates on the Vital stand at the BSDHT Conference in Bournemouth, October 2009.

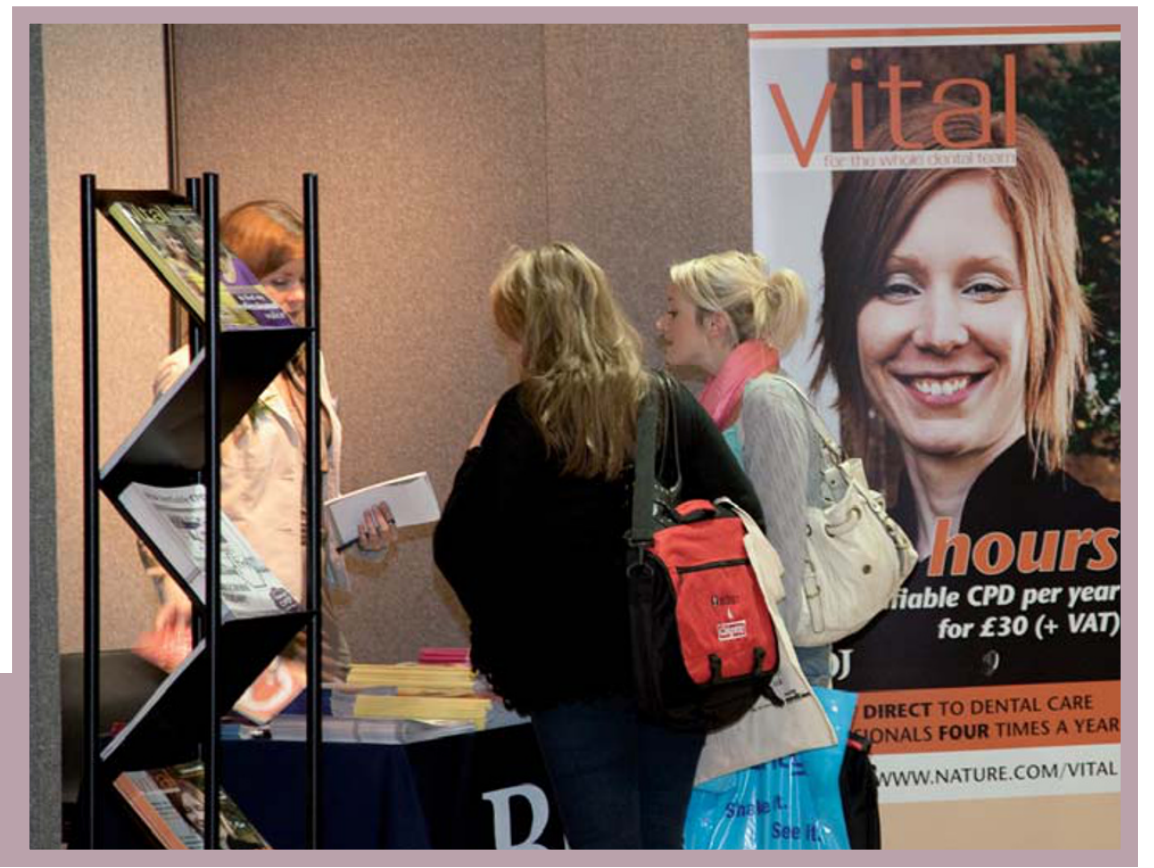




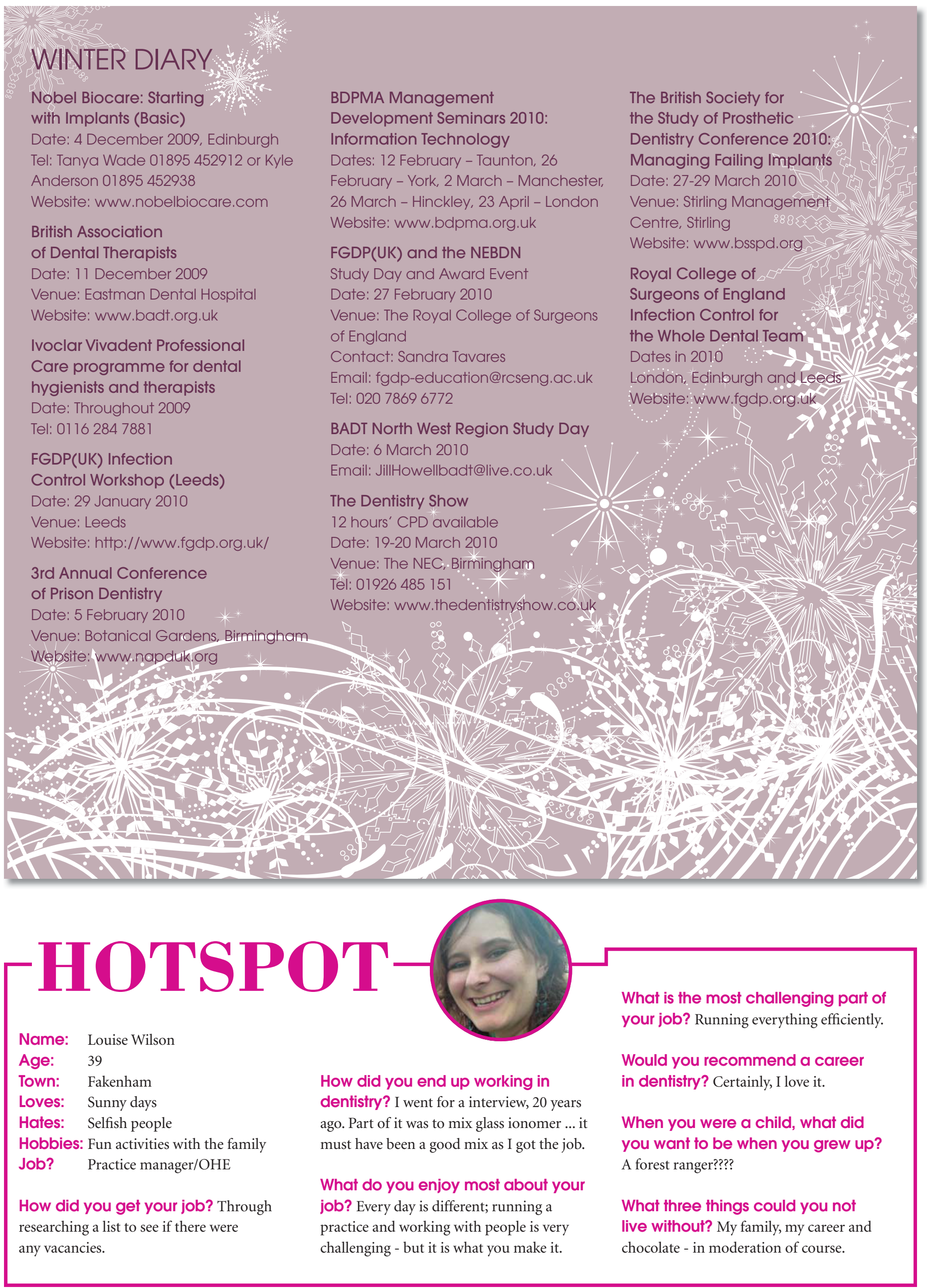

